\title{
ASPECTOS HIDROCLIMÁTICOS E COMPRTAMENTO DA PRECIPITÇÃO NOS MUNICIPIOS DE ACARAÚ E CAMOCIM - CE
}

\author{
Paulo Roberto Silva Pessoa ${ }^{(a)}$, Tarcyana Camara Barroso ${ }^{(b)}$, Giovana Gonçalves Bezerra ${ }^{(c)}$, \\ Luana Braga da Rocha ${ }^{(\mathrm{d})}$
}

(a) Prof. Dr. Curso de Geografia da Universidade Estadual do Ceará - UECE/LGCO, paulorpessoa@ gmail.com

(b) Aluna do Curso de Geografia da UECE - Bolsista ICT/ FUNCAP/UECE, tarcyanabarroso@ gmail.com

(c) Aluna do Curso de Geografia da UECE - Bolsista PRAE/UECE, giovana.gbz@ gmail.com

(d) Aluna do Curso de Geografia da UECE - Bolsista PROMAC/UECE, luana.br@live.com

Eixo: Climatologia em Diferentes Níveis Escalares: Mudanças e Variabilidades

\begin{abstract}
Resumo
As bacias dos Acaraú e Coreaú estão submetidas quase em sua totalidade a sazonalidade do clima semiárido, exceto a sua porção que se localiza a partir do baixo curso destes rios, onde recebem também a contribuição do clima litorâneo e dos sistemas atmosféricos dinâmicos que atuam na faixa litorânea no nordeste. Contudo, este ambiente mesmo não estando submetido à semiaridez climática, recebe influencia dessa condição, uma vez que a maior parte da bacia se localiza nos ambientes semiáridos. A compreensão do funcionamento da dinâmica do tempo e do clima na porção correspondente ao baixo curso desses rios é de importância inequívoca também para entender o comportamento dos ambientes e processos litorâneos associados. O objetivo deste trabalho é descreve e comparar os regimes de precipitação desses municípios localizados no litoral oeste do estado do Ceará.
\end{abstract}

Palavras chave: Regime pluviométrico; bacias hidrográficas; semiaridez.

\section{INTRODUÇÃO}

De acordo com a classificação climática de Köppen (1931), o estado do Ceará apresenta três tipos de clima: BSw'h' (quente e seco, com estação chuvosa no verão, atrasando-se para o outono), Aw'(clima tropical com estação seca de Inverno) e Cw'(clima temperado úmido com Inverno seco), havendo uma predominância em aproximadamente $80 \%$ do tipo BSw'h'. A isoieta de $800 \mathrm{~mm}$ anuais compreende $75 \%$ da sua área total (FUNCEME, 1991) e as médias térmicas anuais variam de $23^{\circ}$ a $27^{\circ} \mathrm{C}$.

Nas áreas correspondentes as bacias dos Acaraú e Coreaú, segundo a classificação de Köppen (1931), predomina o clima tropical chuvoso, (Aw'), com estação invernosa ausente e estação chuvosa concentrada no outono. Esta característica predomina na porção norte dessas bacias, com precipitações variando de 1.000 a $1.600 \mathrm{~mm}$ anuais. Já o clima do tipo quente e semiárido (BSw'h'), com estação chuvosa atrasada para o outono, ocorre na porção sul onde estão as áreas correspondentes ao sertão, onde as precipitações oscilam entre 700 e $1.000 \mathrm{~mm}$.

A bacia do Coreaú está localizada na porção norte-ocidental do Estado. Possuindo os seguintes limites: ao sul as bacias do Poti-Longá e Acaraú, a oeste o Estado do Piauí, a leste a bacia do rio Acaraú e ao norte o Oceano Atlântico. A linha de costa possui uma extensão de aproximadamente $130 \mathrm{~km}$. Figura 01. 


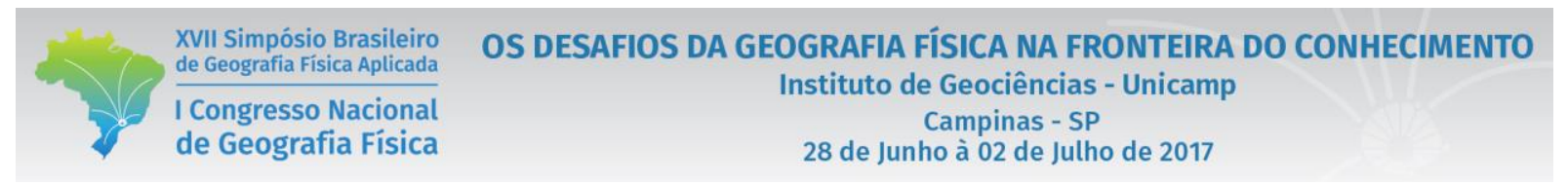

A bacia do Acaraú está localizada no setor norte-ocidental do estado do Ceará, limitando-se a oeste e a sudoeste, respectivamente, com as bacias do Coreaú e do Poti-Longá, a leste e sudeste, com as bacias do Litoral e do Curu. Figura 01.

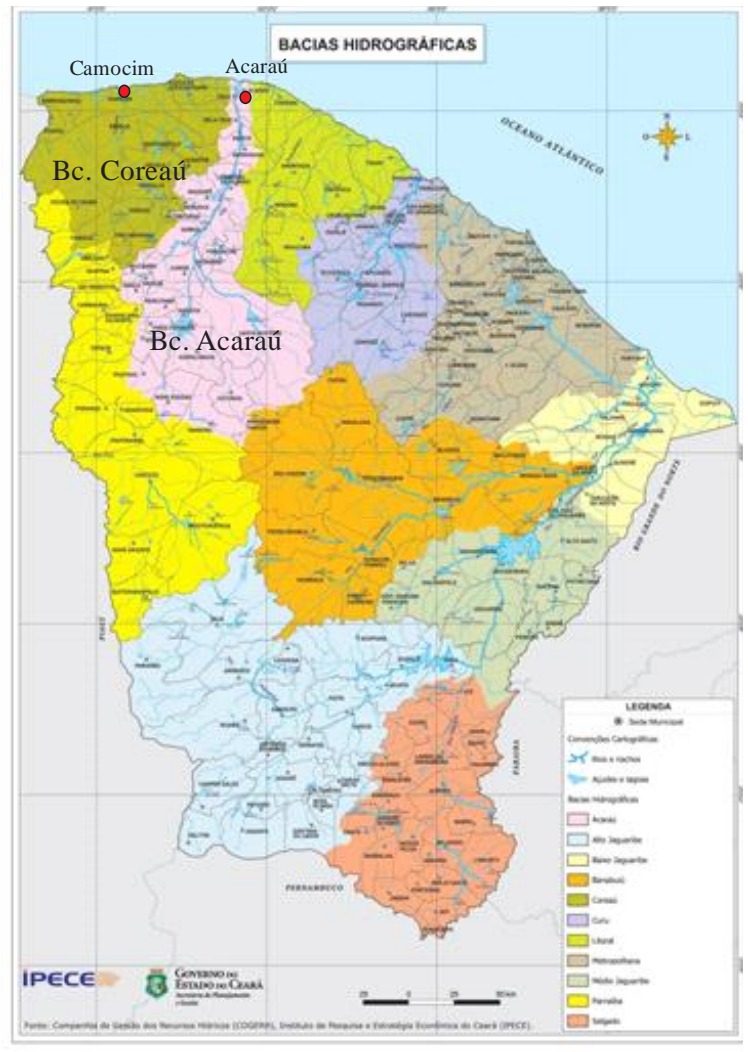

Figura 1 - Bacias hidrográficas do estado do Ceará

\section{METODOLOGIA}

Foram utilizados os dados pluviométricos disponibilizados pela Fundação Cearense de Meteorologia e Recursos Hídricos - FUNCEME, no intervalo compreendido entre 1974 a 2016, do posto pluviométrico da FUNCEME no município de Acaraú e Camocim. O INMET não tem informações de pluviometria de anos anteriores sobre a região estudada.

Os dados brutos dos registros de chuva e temperatura foram devidamente trabalhos em planilhas eletrônicas observando a sua consistência para realização do tratamento estatístico.

Dessa forma foi analisado o comportamento da precipitação nos municípios analisados com base nos dados pluviométricos da FUNCEME, considerando também como elemento da dinâmica do tempo e do clima na região, a atuação dos principais sistemas produtores de chuva e suas variações baseadas nos fenômenos El Nino e Dipolo do Atlântico.

\section{RESULTADOS E DISCUSSÕES}

Para se entender o comportamento do clima de uma região é necessário compreender como as variáveis meteorológicas, que definem o tempo ao longo dos anos se comportam. Dessa forma o tempo é definido como sendo os fenômenos meteorológicos que ocorrem cronologicamente na atmosfera, enquanto o clima pode ser entendido como o estado médio do tempo ao longo de vários anos, como define a Organização Meteorológica Mundial - OMM. 
A região Nordeste do Brasil é considerada semiárida por apresentar substanciais variações temporais e espaciais da precipitação pluviométrica, e elevadas temperaturas ao longo do ano, onde a amplitude térmica anual pode chegar até seis graus. (Azevedo et al., 1998).

A FUNCEME descreve os principais sistemas produtores de chuva no nordeste brasileiro como sendo a Zona de Convergência Intertropical - ZCIT, as Frentes Frias, os Vórtices Ciclônicos de Ar Superior VCAS, as Linhas de Instabilidade, os Complexos Convectivos de Mesoescala - CCM, as ondas de Leste, e as oscilações de 30 e 60 dias. Sendo que destes sistemas o de maior representatividade na composição da precipitação no Ceará é a ZCIT. Tabela 1.

Tabela 1 - Sistemas produtores de chuva no Nordeste brasileiro

\begin{tabular}{|c|l|}
\hline \multicolumn{2}{|c|}{ Sistemas produtores de chuva no Nordeste Brasileiro } \\
\hline ZCIT & $\begin{array}{l}\text { Faixa de nuvens convectivas que migra anualmente de latitudes ao norte } \\
\text { do Equador entre os meses de agosto e setembro. Entre os meses de março } \\
\text { e abril pode chegar até aproximadamente } 2^{0} \text { a } 5^{0} \text { de latitude sul. }\end{array}$ \\
\hline Frentes Frias & $\begin{array}{l}\text { Sistemas de nuvens que se formam na zona de interseção de uma massa de } \\
\text { ar quente com uma massa de ar frio. Ocasionalmente podem chegar até a } \\
\text { costa do Nordeste entre os meses de novembro e janeiro, podendo } \\
\text { provocar um aumento da precipitação nesta região. }\end{array}$ \\
\hline VCAS & $\begin{array}{l}\text { Sistemas meteorológicos que podem durar de } 4 \text { a } 10 \text { dias, formados por } \\
\text { centros de baixa pressão em altitudes acima de 9000m. Geralmente forma- } \\
\text { se nos meses de verão, outono e primavera e tem comprovada participação } \\
\text { no quadro pluviométrico do NE. }\end{array}$ \\
\hline Linhas de instabilidade & $\begin{array}{l}\text { Nuvens do tipo cúmulos que podem causar chuva. Outro fator que pode } \\
\text { contribuir para o incremento das Linhas de Instabilidade, principalmente } \\
\text { nos meses de fevereiro e março, é a proximidade da ZCIT. }\end{array}$ \\
\hline OCM & $\begin{array}{l}\text { A origem desses fenômenos está associada à formação de células } \\
\text { convectivas em condições favoráveis, influenciadas pela topografia e por } \\
\text { fontes de calor. Podem provocar chuvas isoladas e rápidas de intensidade } \\
\text { considerável }\end{array}$ \\
\hline Oscilações de 30 e 60 & $\begin{array}{l}\text { Tem sua origem ligada a TSM e a nebulosidade convectiva que se forma } \\
\text { no Oceano Atlântico e seu deslocamento que se dá de leste para oeste. } \\
\text { Podem produzir precipitações consideráveis nas áreas costeiras no período } \\
\text { de abril até agosto. }\end{array}$ \\
\hline $\begin{array}{l}\text { Sistema atmosférico também conhecido como ondas de Kelvin. Sua } \\
\text { atuação sobre o Nordeste brasileiro pode provocar tanto chuvas como } \\
\text { veranicos que tem impacto direto na agricultura e na pecuária da região. }\end{array}$ \\
\hline
\end{tabular}

Segundo Molion e Bernardo (2002) é a Zona de Convergência Intertropical - ZCIT, o principal mecanismo causador de chuva no Norte do Nordeste do Brasil, que no primeiro semestre desce até $4^{\circ}$ de latitude sul, definindo a estação chuvosa no estado do Ceará, principalmente entre fevereiro e maio. A ZCIT é formada pela confluência dos alísios de NE do Hemisfério Norte e pelos alísios de SE no Hemisfério Sul.

A precipitação na área de estudo possui uma considerável irregularidade espacial e anual. Comprovou-se a ação determinante da ZCIT uma vez que $81 \%$ da precipitação anual se concentra nos meses onde de fato há a influência desse sistema atmosférico. Figura 2 a e b.

Analisando os dados pluviométricos entre 1974 e 2016, agrupando a distribuição das precipitações deste período por meses, foi constatado que $52,7 \%$ de toda precipitação acumulada no intervalo observado, concentra-se nos meses de março a abril. 

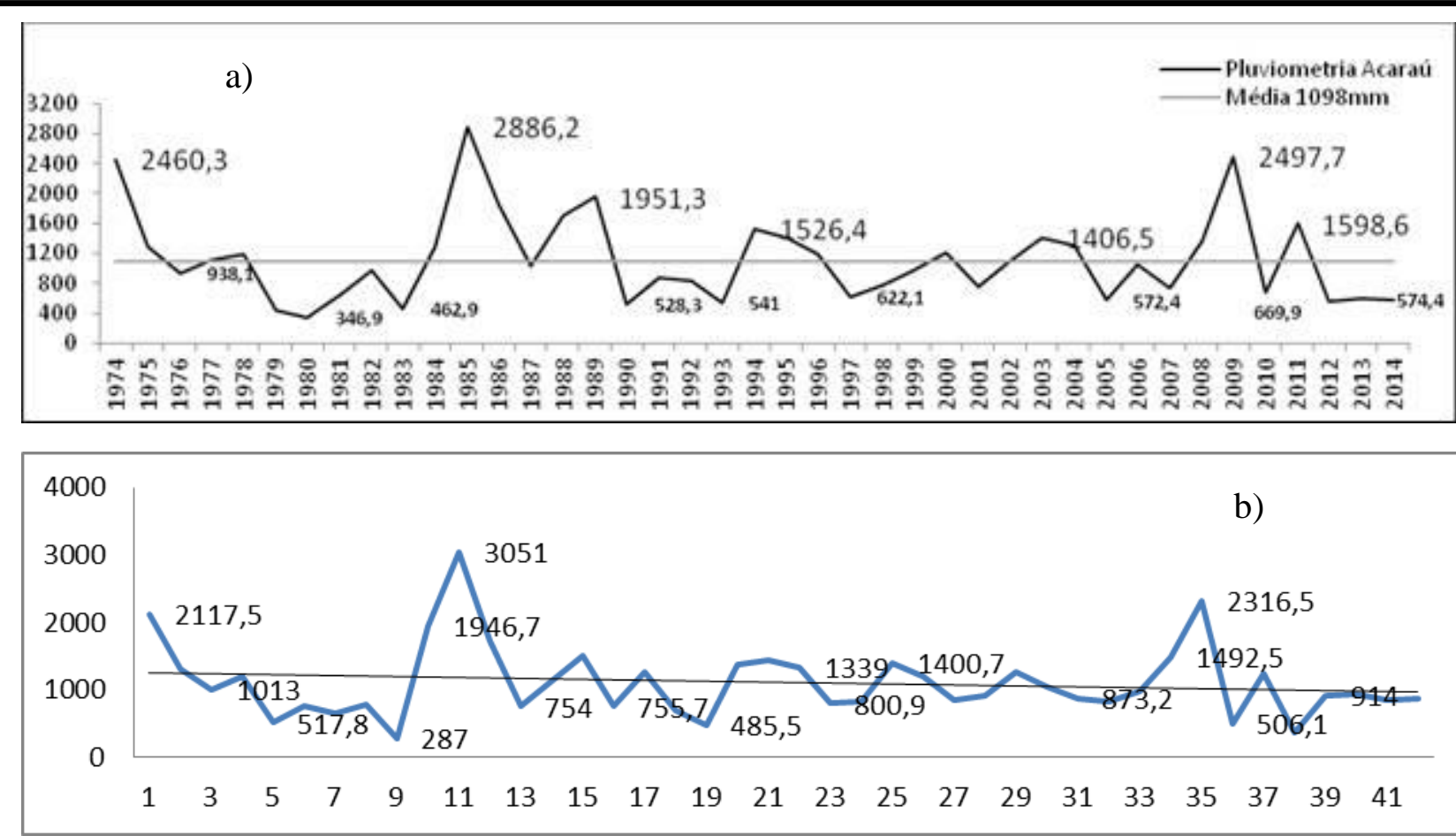

Figura 2 - Precipitação nos municipios de Camocim e Acaraú nos ultimos 40 anos.

A analise das retas de regressão linear, apresentada nas figuras 3 e 4, também demonstra uma forte irregularidade pluviometrica interanual, ou seja, não existe um padrão ou valor que se aproxime de uma média, certamente em função do comportamento dos elementos dinamicos que controlam o tempo e o clima no nordeste brasileiro, especialmente nesta porção do estado do Ceará. Outro fato que merece observação nestes gráficos é a tendencia de diminuição da precipitação no intervalo analisado.

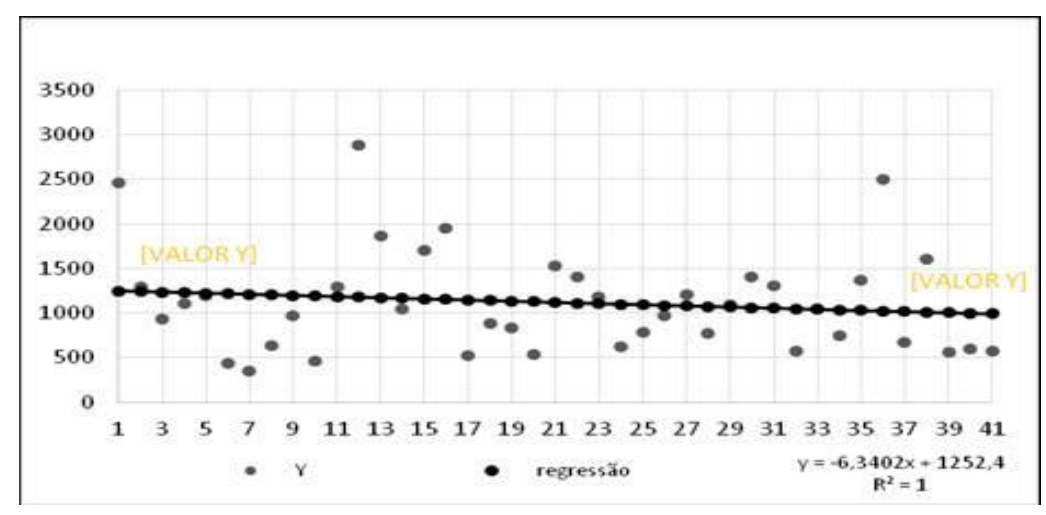

Figura 3 - Reta de regrassão baseadas nos valores de precipitação do municipio de Acaraú no ultimos 40 anos 
Esta condição tem implicações diretas na relação de acumulação de água nos reservatórios (açudes), na acumulação das águas subterraneas na salinização de solos pelo avanço das mares salinas nas áreas estuainas dos rios Coreaú em Camocim e Acaraú no municipio de mesmo nome.

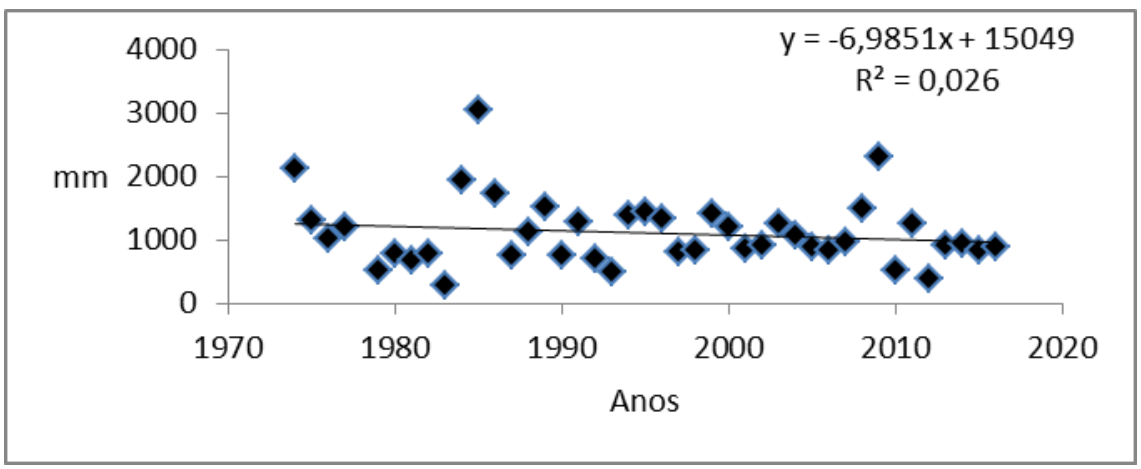

Figura 4 - Reta de regressão baseadas nos valores de precipitação do município de Camocim no últimos 40 anos

\section{BIBLIOGRAFIA}

AZEVEDO, P. V. De; SILVA, B. B., Da; RODRIGUES, M. F. G. Previsão das chuvas de outono no estado do Ceará. Revista Brasileira de Meteorologia, v. 13, n. 1, p. 19-30, 1998.

CEARÁ. COGERH. Caderno regional da bacia do Acaraú, 2009. Disponível em 18/05/2015.

CEARÁ. COGERH. Caderno regional da bacia do Coreaú, 2009. Disponível em 18/05/2015.

CEARÁ. IPECE. http://www.ipece.ce.gov.br/publicacoes/perfil_basico/perfil-basico-municipal-2014.html. Acessado em 18/05/2015.

FUNCEME, 1991. Análise preliminar do fator mais provável da medida de tendência central das series anuais de precipitação no Ceará. Fortaleza, Fundação Cearense de Meteorologia e Recursos Hídricos, 1991.

EMPRESA BRASILEIRA DE PESQUISAS AGROPECUÁRIAS - EMBRAPA: Agroindústria Tropical. Contexto geoambiental das Bacias hidrográficas dos rios Acaraú, Curu e baixo Jaguaribe - estado do Ceará. Fortaleza. 52p. Documentos 101, 2005.

KÖPPEN, W. Grundriss der klimakunde. Berlin: W. Guyter, 1931. 390p.

LACERDA, L.D. GODOY, M.D; MAIA, L.P. Mudanças climáticas globais. Ciência Hoje. 2010.

MOLION, L.C.B.; BERNARDO, S.O. Uma revisão da dinâmica das chuvas no Nordeste Brasileiro. Revista Brasileira Meteorologia, 17(1)1-10, 2002. 